\title{
Reply to the letter
}

\author{
Michiko Sugita ${ }^{1}$ (D)
}

Received: 24 December 2019 / Accepted: 4 January 2020 / Published online: 30 January 2020

(c) Japanese Society of Anesthesiologists 2020

\section{To the Editor:}

I would like to appreciate the readers for their helpful comments on our manuscript [1].

As they pointed it out, we performed an incorrect description by mistake. The correct formula for calculating $\mathrm{GV}$ is as follows: $\mathrm{GV}(\mathrm{ml})=27.0+14.6 \times \mathrm{CSA}\left(\mathrm{cm}^{2}\right)-1.28 \times$ age (year).

I am grateful for the opportunity to correct our description.

\section{Reference}

1. Sugita M, Matsumoto M, Tsukano Y, Fukunaga C, Yamamoto T. Gastric emptying time after breakfast in healthy adult volunteers using ultrasonography. J Anesth. 2019;33:697-700.

Publisher's Note Springer Nature remains neutral with regard to jurisdictional claims in published maps and institutional affiliations.

This reply refers to letter to the editor available at doi:https://doi. org/10.1007/s00540-020-02735-5.

Michiko Sugita

msugita@kumamoto-u.ac.jp

\footnotetext{
Department of Anesthesiology, Kumamoto University Hospital, 1-1-1 Honjo, Chuo-ku, Kumamoto 860-8556, Japan
} 